\title{
Complex Neurological Decision
}

\author{
Ghassan Haddad* \\ Serhal Hospital, Lebanon \\ *Corresponding author: Ghassan Haddad, Serhal Hospital, Lebanon
}

Submission: May 15, 2018; Published: May 22, 2018

\section{Editorial}

Neurologists are faced with one great challenge when facing patients with atrial fibrillation who developed an acute ischemic stroke. One question arises.

When to initiate or resume anticoagulation to prevent a recurrent stroke or embolization?

Review of the literature reveals 2 views.

1. The first view was a Cochrane reviews done in 2008 that showed that early anticoagulation within two weeks of stroke onset was associated with fewer recurrent strokes compared to no anticoagulation but at the costs of increased symptomatic intracranial hemorrhages. The conclusion was that early anticoagulation did not improve outcomes [1].

Another studies done by Italians scientist showed that early anticoagulations within 48 hours of stroke had no benefit compared to aspirin or placebo [2].

2. The second view was outlined in 2 major studies:

a. The first study is The Virtual International Stroke Trials Archive (VISTA), a cohort analysis of data from more than 10,000 patients with ischemic strokes and atrial fibrillation at 2 days after a stroke had a better outcome and associated with lower recurrent stroke and death [3].

b. The second study is The Early Recurrence and Cerebral Bleeding in Acute Ischemic Stroke and AF (RAF) that showed that antocoagulations started between 4 and 14 days after stroke had a better outcome with reduced stroke, systemic embolisation, major extracranial bleeding and symptomatic intracranial bleeding [4].

Factors that might influence the Neurologist decision on which view to adopt include the CHA2DS2VAS tool. This tool created by Dr Lips and colleagues from the University of Birmingham may be helpful [5].

\section{A. CHA2DS2VAS tool}

In this tool, every letter refers to a condition that patients with stroke have as described in the table above and each condition is assigned a score.
For example the letter $\mathrm{C}$ in the tool stands for Congestive heart failure (CHF) and patients with CHF are assigned a score of 1 . A stands for Age and is assigned a score of 2.

Totals are them calculated for each patient and review of the percentage of ischemic event is obtained from Table 1. For patients with low risk i.e. no associated medical conditions listed from table one, these patients are at a zero risk of having a recurrent Thromboembolic Events (TE) and hence a delay in anticoagulation to 7 days or more may be justified.

\section{Table 1.}

\begin{tabular}{|c|c|}
\hline $\mathbf{C H A}_{\mathbf{2}} \mathbf{D S}_{\mathbf{2}}$-VAS Score & Number of TE events \\
\hline 0 & 0 \\
\hline 1 & 1 \\
\hline 2 & 3 \\
\hline 3 & 8 \\
\hline 4 & 4 \\
\hline 5 & 3 \\
\hline 6 & 2 \\
\hline 7 & 2 \\
\hline 8 & 1 \\
\hline 9 & 1 \\
\hline
\end{tabular}

Table 2.

\begin{tabular}{|c|c|}
\hline \multicolumn{2}{|c|}{ CHA2DS2VAS tool } \\
\hline Risk Factor & Score \\
\hline $\begin{array}{c}\text { Congestive heart failure/LV } \\
\text { dysfunction }\end{array}$ & 1 \\
\hline Hypertension & 1 \\
\hline Age $\geq 75 y$ & 2 \\
\hline Diabetes mellitus & 1 \\
\hline Stroke/TIA/TE & 2 \\
\hline $\begin{array}{c}\text { Vascular disease(prior myocardial } \\
\text { infarction, peripheral artery } \\
\text { disease, or aortic plaque) }\end{array}$ & 1 \\
\hline Age 65-75y & 1 \\
\hline Sex category (i.e. female gender) & 1 \\
\hline
\end{tabular}


For patients with intermediate risk, i.e. a total score of 1-2 are at a moderate risk of having a recurrent Thromboembolic Events (TE) and hence a delay in anticoagulation to 4 days or more may be justified. For patients with multiple medical conditions listed in Table 2 i.e. a total score of 3 or more, are at a high rate of recurrence of ischemic event and hence early anticoagulation with 2 days delay may be justified.

\section{References}

1. Sandercock PA, Counsell C, Kamal AK (2008) Cochrane Database Syst Rev (4): CD000024.
2. Paciaroni M, Agnelli G, Micheli S, Caso V (2007) Stroke. 38(2): 423-430.

3. Abdul-Rahim AH, Fulton RL, Frank B, Tatlisumak T, Paciaroni M, et al. (2015) Eur J Neurol 22(7): 1048-1055. doi: 10.1111/ene.12577.

4. Paciaroni M, Agnelli G, Falocci N, Caso V, Becattini C, et al. (2015) Stroke. 46(8): 2175-2182.

5. Lip GY, Nieuwlaat R, Pisters R, Lane DA, Crijns HJ (2010) Chest. 137(2): 263-272.
Creative Commons Attribution 4.0 International License

For possible submissions Click Here

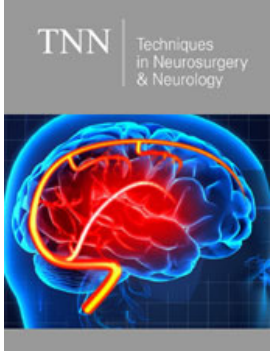

Techniques in Neurosurgery \& Neurology

\section{Benefits of Publishing with us}

- High-level peer review and editorial services

- Freely accessible online immediately upon publication

- Authors retain the copyright to their work

- Licensing it under a Creative Commons license

- Visibility through different online platforms 